\title{
Retinoblastoma: Socio-Demographic, Clinical and Therapeutic Aspects in the Hemato-Oncology Unit of the Department of Pediatrics of Donka National Hospital, Guinea
} \author{
Boubacar Togo ${ }^{3}$, Mamadou P. Diallo ${ }^{4}$ \\ ${ }^{1}$ Department of Pediatrics, National Hospital Donka, Conakry, Guinea \\ ${ }^{2}$ Department of Pediatrics, Ignace Deen Hospital, Conakry, Guinea \\ ${ }^{3}$ Departmentof Pediatrics, Gabriel Toure Hospital, Bamako, Mali \\ ${ }^{4}$ Medical and Health Counseling Center, Conakry, Guinea \\ Email: docteumama@gmail.com
}

Aïssata Barry1, Mamadou M. Diop1, Mamadou A. Doukoure1, Emmanuel Camara1, Saliou B. Diallo', Narcisse V. Gateu Tadjom¹, Fatoumata Barry ${ }^{1}$, Hasmiou Dia ${ }^{2}$,

How to cite this paper: Barry, A., Diop, M.M., Doukoure, M.A., Camara, E., Diallo, S.B., Gateu Tadjom, N.V., Barry, F., Dia, H., Togo, B. and Diallo, M.P. (2020) Retinoblastoma: Socio-Demographic, Clinical and Therapeutic Aspects in the Hemato-Oncology Unit of the Department of Pediatrics of Donka National Hospital, Guinea. Open Journal of Pediatrics, 10, 561-569.

https://doi.org/10.4236/ojped.2020.103057

Received: August 25, 2020

Accepted: September 24, 2020

Published: September 27, 2020

Copyright $\odot 2020$ by author(s) and Scientific Research Publishing Inc. This work is licensed under the Creative Commons Attribution International License (CC BY 4.0).

http://creativecommons.org/licenses/by/4.0/

(c) (i) Open Access

\begin{abstract}
Introduction: Retinoblastoma is one of the pediatric malignancies and its treatment is still challenging. The objective of this study was to highlight the sociodemographic, clinical, and therapeutic aspects of retinoblastoma at the Donka Paediatric Haematology/Oncology unit in Donka university hospital, Guinea, and thereby highlight the conditions of this malignancy in this country. Methods: This was a retrospective study over 3 years (January 1, 2017 to December 31, 2019). The study population was all retinoblastoma patients who were treated in this unit. Socio-demographic, clinical, and therapeutic data were analyzed. Results: Out of 210 pediatric patients followed up for cancer in this unit during the period, retinoblastoma accounted for 46 (22\%). The patient age at diagnosis was 35.17 months (range: $3-132$ months). At admission, metastases were observed in 16 patients (35\%): 14 with brain metastases and 2 with lymph node metastases. Preoperative chemotherapy was employed in 38 (83\%), tumor resection was performed in 20 patients (43\%), and postoperative chemotherapy was performed in 19 patients. As for the prognosis, remission in 9, death in 14, and treatment discontinuation in 15. Only one patient had health insurance (2\%). Conclusion: In this region of Guinea, retinoblastoma is the most common ocular tumor in children. Its diagnosis is easy: strabismus and leukocoria are the early signs of retinoblastoma. The prognosis depends on how early the diagnosis is made. Physicians, care-givers, and family members should be aware of the nature of this malig-
\end{abstract}


nancy and social education/message as such is necessary.

\section{Keywords}

Retinoblastoma, Leukocoria, Chemotherapy, Enucleation

\section{Introduction}

Retinoblastoma is a malignant tumor that develops at the expense of embryonic retinal cells or retinoblasts [1]. It affects infants and young children in general, before the age of 5 years [2] [3] [4]. Globally, the overall incidence of retinoblastoma is estimated at 1/16,000 live births, or about 8000 new cases each year, including at least 2000 new cases in Africa [5]. The incidence of retinoblastoma is unevenly distributed. It is higher in low-income countries than in high-income countries [6].

There are two forms of retinoblastoma: the sporadic form and the hereditary form. Sporadic cases are always unilateral and account for $60 \%$ of patients, with a median age at diagnosis of about two years, while the hereditary forms are mostly bilateral and account for $40 \%$ of patients, with a median age at diagnosis of about one year [2].

The diagnosis of retinoblastoma is essentially clinical and is most often revealed by two warning signs: Leukocoria and strabismus. These signs allow an early diagnosis by a simple examination of the fundus. Imaging plays an important role in the diagnosis of atypical or advanced forms of retinoblastoma with an inaccessible fundus [7].

In industrialized countries, the cure rate is about $95 \%$, the vast majority of cases are diagnosed at an early stage of the disease, whereas in poor countries life-threatening retinoblastoma is a major challenge and is due to late diagnosis [5].

The objective of this study was to highlight the socio-demographic, clinical and therapeutic aspects of retinoblastoma at the Pediatric Hematology and Oncology Unit in Donka of Guinea.

\section{Methods}

The pediatric hematology and oncology unit of Donka national hospital in Guinea was the setting for this study. This unit is located on the grounds of Donka National Hospital republic of Guinea. It has a capacity of 8 inpatient beds and a day hospital. The staff includes 3 onco-pediatricians, 5 state nurses and 1 technical health worker. The hematology and oncology unit is supported by the Franco-African pediatric oncology group (GFAOP), which provides medicines and staff training. This unit was opened in 2012. It became functional in 2016 with the training of oncologists. It is the only pediatric cancer care unit in Guinea. It was a retrospective and descriptive study over 3 years from January 1 , 
2017 to December 31, 2019.

The study population was all retinoblastoma patients followed in the unit, and whose records were usable (records of patients who have completed a full retinoblastoma extension workup). Patients who were lost to follow-up (Patients who have not been heard from and who have not undergone an extension workup) were not included in the study.

The variables studied were:

- Socio-demographic data (sex, age, place of residence of patients);

- Clinical data (mode of discovery, reason and time of consultation, itinerary, stage of the disease, laterality, fundus results);

- Paraclinical data (biology, ultrasound and brain orbital CT data).

The data were collected on a pre-established and validated survey form and entered into Word and Excel and then analyzed on Epi info 7.2.

\section{Ethical Considerations}

The agreement of the service managers was obtained before the surveys began. A working protocol was drawn up and validated by the hospital authorities and the pediatric chair. The confidentiality of the data collected was respected and the personal information collected remained confidential.

\section{Results}

\subsection{Socio-Demographic Aspects}

Out of 210 patients followed for cancer we registered 46 cases of retinoblastoma (21.9\%) (Table 1). The patients were distributed as follows: 13 in 2017 (28.2\%), 16 in 2018 (34.8\%) 17 in 2019 (37\%). The average age of our patients was 35.17 months with extremes of 3 months and 132 months. There were $52.2 \%$ girls and $47.8 \%$ boys with a $\mathrm{B} / \mathrm{G}$ sex ratio of 0.9 . The age range of 25 to 59 months was the most representative with 26 cases $(56.52 \%)$. For 31 patients there was no notion of consanguinity between the 2 parents (67.3\%). Eleven patients had relatives with a 2 nd degree consanguinity (24\%). Four patients had a 1st degree consanguinity $(8.7 \%)$.

\subsection{Clinical Aspects}

The median time to visit was 165 days with extremes of 7 days and 4 years. The median time to diagnosis was 168 days with extremes of 8 days and 4 years. Median time to treatment was 197 days with extremes of 15 days and 4 years. At admission: 28 patients (60.87\%) had Exophthalmos, 16 patients $(34.78 \%)$ had Leukocoria, 4 patients (8.7\%) had Buphtalmos and 4 patients (8.7\%) had Strabismus. Sixteen of our patients had metastases (35\%). Of these 14 (30.5\%) had brain metastases and 2 patients $(4.5 \%)$ had lymph node metastases. Sixty-five patients $(65 \%)$ had no metastases. We registered 14 patients $(30.43 \%)$ with intra-orbital forms, 32 patients $(69.57 \%)$ with extra orbital forms. Forty patients $(87 \%)$ had a unilateral shape and 6 patients (13\%) had a bilateral shape. 
Table 1. Incidence of retinoblastoma compared to other childhood cancers.

\begin{tabular}{ccc}
\hline Cancers & Number & Percentage \\
\hline Burkitt lymphoma & 48 & 22.86 \\
Retinoblastoma & 46 & 21.90 \\
Nephroblastoma & 36 & 17.14 \\
Acute lymphoblastic leukemia & 35 & 16.67 \\
Hodgkin lymphoma & 16 & 7.62 \\
Rhabdomyosarcoma & 5 & 2.38 \\
Osteosarcoma & 4 & 1.90 \\
Hepatoblastoma & 4 & 1.90 \\
Sacrococcygeal teratoma & 4 & 1.90 \\
Cerebral tumor & 4 & 1.91 \\
Neuroblastoma & 3 & 1.43 \\
Tcute myelobastic leukemia & 3 & 1.43 \\
Carcinoma of the nasopharynx & 1 & 0.48 \\
Histiocytosis & 210 & 0.48 \\
\hline Total & 3 & 100 \\
\hline
\end{tabular}

\subsection{Therapeutic Aspects}

Thirty-eight patients (82.6\%), had preoperative chemotherapy 20 patients (43.48\%) were enucleated 19 patients $(41.3 \%)$ had postoperative chemotherapy. There were 9 patients (19.5\%) were in remission, 14 patients (30.43\%) died, 15 patients (36.39\%) discontinued treatment (Table 2) and 8 patients (17.39\%) are currently being treated.

Of the patients who died 12/14 had extra-orbital forms (85.7\%), 6/14 (42.8\%) had brain metastases, $2 / 14$ (14.2\%) had lymph node metastases. 2/14 (14.2\%) had bilateral forms and $1 / 14(7.14 \%)$ had intraorbital forms. Of the patients who died, 9/14 (64.2\%) died during preoperative chemotherapy, 2/14 (14.22\%) died during postoperative chemotherapy, $1 / 14(7.14 \%)$ died on admission prior to the start of treatment and 3/14 (21.42\%) died during palliative treatment.

Only one of our patients had health insurance (2.17\%). For the other patients, the parents were responsible for their children's health care.

\section{Discussion}

During this study period, 210 cases of all cancers were recorded. Retinoblastoma ranked second with a frequency of $21.90 \%$ (Table 1). Our frequency is higher than that of Ngatchoukpo et al. in Central Africa [8] and Constant et al. in 2018 [9] who found $5.4 \%$ and $12.07 \%$ respectively. The pediatric hematology and 
Table 2. Distribution of patients by time to discontinue treatment.

\begin{tabular}{ccc}
\hline Time to discontinue treatment & Number & Percentage \\
\hline Before the introduction of chemotherapy & 7 & 46.7 \\
During pre-operative chemotherapy & 7 & 46.7 \\
After enucleation before post-operative chemotherapie & 1 & 6.6 \\
Total & 15 & 100 \\
\hline
\end{tabular}

oncology unit in Donka Guinea is a young unit. Before the creation of the unit, several cases of retinoblastoma were treated in Bamako (Mali) at the Institute of Tropical Ophthalmology of Africa (IOTA). The population and the health personnel are informed of the opening of the unit in Conakry, which increases the number of consultations.

The mean age of diagnosis was 35.17 months with extremes of 3 months and 132 months. This result is similar to that of Berete et al. in 2018 in Treichville who found a mean age of 35.5 months [10].

The age range of 25 to 59 months was the most representative with 26 cases, a frequency of $56.52 \%$. This result is different from that found by Fernandes et al. in the United States in 2018 [11] who reported that the 0 - 1 year age group was the most affected. This difference could be explained by the early diagnosis in developed countries. Most patients consulted as soon as the first signs appeared. Lack of awareness of retinoblastoma in peripheral center delays the diagnosis of retinoblastoma.

The median time to visit was 165 days and the median time to diagnosis was 168.5 days. These results are higher than those found by Njuguma et al. in 2016 in Kenya [12] in their study who reported a median time to diagnosis of 30 days and a median time to diagnosis of 109 days. This may be explained by the fact that the signs and symptoms of retinoblastoma are not easily recognized by parents and health care staff.

The median processing time was 158 days. This result is higher than that found by Lukamba et al. [13] in 2018 in a study conducted in Côte d'Ivoire and the Democratic Republic of Congo, who reported a median time of 31 days. This could be related to the delay in consultation and diagnosis encountered in our study.

We found the notion of consanguinity between the parents in 15 cases, i.e. $32.61 \%$. This result is identical to the one reported by Frikha et al. in Tunisia [14] who noted 15 cases or $37.5 \%$. On the other hand, it is lower than that found by Kaka et al. in Niger in 2016 [15] who reported 45 cases or $78.6 \% .10 .52 \%$ of patients had a family history of retinoblastoma, i.e. $4.35 \%$ in siblings and $6.52 \%$ in ancestors. This result is higher than that found by Zomor et al. in Egypt in 2015 [16] who reported in their study that $5.7 \%$ of patients had a family history of retinoblastoma. In the literature $40 \%$ of retinoblastoma cases are hereditary. They are caused by a germline mutation in the RB1 gene [17] [18]. The presence 
or absence of a family history is an important factor in determining the likelihood of retinoblastoma occurrence. The probability of retinoblastoma occurring in patients with a family history of bilateral retinoblastoma is $90 \%$. This probability is $15 \%$ for cases of unilateral retinoblastoma [17] [19]. Follow-up of children with a family history of retinoblastoma is necessary for early detection.

The unilateral form predominated in our study with $87 \%$ of the cases against $13.0 \%$ for the bilateral form. Unilateral retinoblastoma is the most common form as reported in the studies by Singh et al. in 2018 [20].

Clinical signs were dominated by exophthalmos 28 cases $(37.78 \%)$. The presence of extra orbital forms 32 (69.57\%), the presence of metastases 16 cases indicates a delay in the diagnosis of retinoblastoma at the Pediatric Hematology and Oncology Unit in Donka. Kim and Park in Korea in 2015 found leukocoria as the most frequent sign with $56 \%$ of cases [21]. On the other hand, exophthalmos was the most frequent reason for consultation $61 \%$ in a study conducted by Berete et al. in Ivory Coast in 2018 [10]. This result could be explained by the fact that children in Africa consult late in the course of the disease due to parents' ignorance of the first clinical signs of retinoblastoma, but also to the habit of consulting the traditional therapist first. It is after the failure of a long course of traditional treatment that patients are referred to a health facility. They are seen in a specialized structure at a late stage of the disease.

The extra-ocular form predominated in our study, 32 cases or $69.57 \%$ Among the 46 patients, there were $16(34.79 \%)$ metastases. This result is different from that found by Chebbi et al. in Tunisia in 2014 [22] who reported 87\% intraocular form. Lu et al. in the United States in 2018 [23] reported 9 patients with metastases (3.9\%). The high number of extra-orbital forms at the time of diagnosis and the presence of metastases indicate a delay in diagnosis. Early diagnosis of cancers in general and retinoblastoma in particular is one of the major challenges in the management of childhood cancer in Guinea. The delay in diagnosis can be explained by the population's lack of knowledge of RB and health workers' lack of awareness of early signs. In fact, all our patients consulted a health structure as soon as the first symptom noticed by the parents appeared. The recourse to self-medication in case of failure of the 1st consultation in a health structure favours the delay of diagnosis and treatment.

The management of retinoblastoma is multidisciplinary. It involves the pediatric oncologist, the ophthalmologist, the radiotherapist, the ocularist, the anatomopathologist, the psychologist, the radiologist.

In our study, $82.6 \%$ of patients received preoperative chemotherapy, enucleation was performed in 20 patients $(43.48 \%)$, and $41.30 \%$ of patients received postoperative chemotherapy. The high proportion of preoperative chemotherapy and enucleation performed would be explained by the fact that most of our patients diagnosed with an exophthalmos that did not allow for conservative treatment. Conservative treatment and radiotherapy are not done in Guinea. All cases with bilateral form requiring conservative treatment and cases of retinob- 
lastoma requiring radiotherapy were referred outside Guinea.

The prognosis is still bleak in developing countries. We recorded 14 deaths $(30.43 \%)$. This finding is found in most African studies, notably that of Kazadi Lukusa et al. [24] in Congo in 2012, who found a mortality rate of $90 \%$. This high number of deaths can be explained by the delay in diagnosis (high extraocular forms, presence of metastases) and the absence of certain therapies such as radiotherapy in Guinea. Parents do not have the means to evacuate their children due to the cost of radiotherapy.

Fifteen patients dropped out of treatment by $32.61 \%$ (Table 2). The absence of a home for parents who do not live in Conakry and the high cost of check-ups such as CT scans are factors that encourage the abandonment of treatment. The pediatric hematology and oncology unit in Conakry receives half-yearly drug donations from the Franco-African pediatric oncology group, which reduces the cost of chemotherapy. In the event of a drug break, chemotherapy is paid for by the family.

Our study has some limitations: we did not have enough recurrences to assess the survival of our patients. As the study period was from January 2017 to December 2019, some of our patients were still being treated at the time of inclusion. For these patients, we were unable to assess the evolution of their pathology.

We had 36.96\% remission. Berete et al. [10] in Ivory Coast in 2018 reported a remission rate of $25 \%$. This result could be explained not only by a delay in diagnosis and treatment but also by frequent drug stockouts.

\section{Conclusion}

In this region of Guinea, retinoblastoma is the most common ocular tumor in children. Its diagnosis is easy: strabismus and leukocoria are the early signs of reti-noblastoma. The prognosis depends on how early the diagnosis is made. Physicians, care-givers, and family members should be aware of the nature of this malignancy and social education/message as such is necessary.

\section{Acknowledgements}

We would like to thank the Franco-African Pediatric Oncology Group for all its support in the research and care of children with cancer.

\section{Conflicts of Interest}

The authors declare no conflicts of interest regarding the publication of this paper.

\section{References}

[1] Sow, A.S., Ndoye Roth, P.A., Moreira, C., et al. (2014) Thérapeutique du rétinoblastome: Expérience sénégalaise. Journal Français D’ Ophtalmologie, 37, 381-387. https://doi.org/10.1016/j.jfo.2013.12.009 
[2] Boubekeur, A., Louhibi, L., Mahmoud, K., et al. (2012) Molecular Study of Retinoblastoma in the Algerian Population. Screening of $\mathrm{Rb}$ Gene in Constitutional and $\mathrm{Tu}$ moral Level. Bulletin du Cancer (Paris), 99, 127-135. https://doi.org/10.1684/bdc.2011.1529

[3] Dimaras, H. and Corson, T.W. (2019) Retinoblastoma, the Visible CNS Tumor: A Review: DIMARAS and CORSON. Journal of Neuroscience Research, 97, 29-44. https://doi.org/10.1002/jnr.24213

[4] Levy, D., Aerts, I., Michon, J., et al. (2014) Childhood Cancer: Progress But Prognosis Still Very Unequal. Example of Retinoblastoma and High-Risk Neuroblastoma. Bulletin du Cancer (Paris), 101, 250-257. https://doi.org/10.1684/bdc.2014.1904

[5] Traoré, F., Sylla, F., Togo, B., et al. (2018) Treatment of Retinoblastoma in Sub-Saharan Africa: Experience of the Pediatric Oncology Unit at Gabriel Toure Teaching Hospital and the Institute of African Tropical Ophthalmology, Bamako, Mali. Pediatric Blood \& Cancer, 65, e27101. https://doi.org/10.1002/pbc.27101

[6] Bey, P., Chenge, G., Desjardins, L., et al. (n.d.) Retinoblastoma: An Exemplary Tumour in Young Children That Can Be Cured in Low-Income Countries. 4.

[7] Kerrouche, K. (2017) Les aspects épidémiologiques et cliniques du rétinoblastome dans l'ouest Algérien. Doctorat en Medecine.

[8] Ngatchoukpo, V.N., Doumgba, A.D. and Gaudeuille, A. (2018) Current Aspects of the Management of Malignant Childhood Tumors in Bangui: About 56 Cases. Research and Analysis Journal, 1.

[9] Constant, S.T.Y., Koffi, B.P.E.F., Serge, I.B.G., et al. (2018) Epidemiological Particularities and Indications of the Mutilating Surgery of the Eyeball in Abidjan (Ivory Coast). Open Journal of Ophthalmology, 8, 91-96. https://doi.org/10.4236/ojoph.2018.82013

[10] Bérété, C.R., Dibi, M., Koman, E., et al. (2018) Aspects récents du rétinoblastome en Côte d'ivoire évaluation de cas au CHU de Treichville de 2013-2016.

[11] Fernandes, A.G., Pollock, B.D. and Rabito, F.A. (2018) Retinoblastoma in the United States: A 40-Year Incidence and Survival Analysis. Journal of Pediatric Ophthalmology and Strabismus, 55, 182-188. https://doi.org/10.3928/01913913-20171116-03

[12] Njuguna, F., Martijn, H., Langat, S., et al. (2016) Factors Influencing Time to Diagnosis and Treatment among Pediatric Oncology Patients in Kenya. Pediatric Hematology and Oncology, 33, 186-199. https://doi.org/10.3109/08880018.2016.1169566

[13] Lukamba, R.M., Yao, J.-J.A., Kabesha, T.A., et al. (2018) Retinoblastoma in Sub-Saharan Africa: Case Studies of the Republic of Côte d'Ivoire and the Democratic Republic of the Congo. Journal of Global Oncology, 4, 1-8. https://doi.org/10.1200/JGO.17.00056

[14] Frikha, H., Chaari, N., Nasr, C., et al. (2009) Place de la radiothérapie dans le traitement du rétinoblastome: A propos de 40 cas. Cancer/Radiothérapie, 13, 30-36. https://doi.org/10.1016/j.canrad.2008.08.001

[15] Kaka, H.Y., et al. (2016) Les particularités du rétinoblastome au Niger. European Scientific Journal, 12, 84. https://doi.org/10.19044/esj.2016.v12n3p84

[16] Zomor, H.E., Nour, R., Alieldin, A., et al. (2015) Clinical Presentation of Intraocular Retinoblastoma; 5-Year Hospital-Based Registry in Egypt. Journal of the Egyptian National Cancer Institute, 27, 195-203. https://doi.org/10.1016/j.jnci.2015.09.002

[17] National Cancer Institute. 
http://seer.cancer.gov/csr/1975_2010/browse_csr.php?sectionSEL=29\&pageSEL=sec t_29_zfig.01.html

[18] Melamud, A., Palekar, R. and Singh, A. (2006) Retinoblastoma. American Family Physician, 73, 1039-1044.

[19] MacCarthy, A., Draper, G.J., Steliarova-Foucher, E., et al. (2006) Retinoblastoma Incidence and Survival in European Children (1978-1997). Report from the Automated Childhood Cancer Information System Project. European Journal of Cancer, 42, 2092-2102. https://doi.org/10.1016/j.ejca.2006.06.003

[20] Singh, U., Katoch, D., Kaur, S., et al. (2018) Retinoblastoma: A Sixteen-Year Review of the Presentation, Treatment, and Outcome from a Tertiary Care Institute in Northern India. Ocular Oncology and Pathology, 4, 23-32.

https://doi.org/10.1159/000477408

[21] Kim, J.-Y. and Park, Y. (2015) Treatment of Retinoblastoma: The Role of External Beam Radiotherapy. Yonsei Medical Journal, 56, 1478.

https://doi.org/10.3349/ymj.2015.56.6.1478

[22] Chebbi, A., Bouguila, H., Boussaid, S., et al. (2014) Le profil clinique du rétinoblastome en Tunisie. Journal Français D' Ophtalmologie, 37, 442-448.

https://doi.org/10.1016/j.jfo.2014.01.009

[23] Lu, J.E., Francis, J.H., Dunkel, I.J., et al. (2018) Metastases and Death Rates after Primary Enucleation of Unilateral Retinoblastoma in the USA 2007-2017. British Journal of Ophthalmology, 103, 1272-1277. https://doi.org/10.1136/bjophthalmol-2018-312915

[24] Kazadi Lukusa, A., Aloni, M.N., Kadima-Tshimanga, B., et al. (2012) Retinoblastoma in the Democratic Republic of Congo: 20-Year Review from a Tertiary Hospital in Kinshasa. Journal of Cancer Epidemiology, 2012, Article ID: 920468. https://doi.org/10.1155/2012/920468 